\title{
Introduction \\ The typology and semantics of locative predicates: posturals, positionals, and other beasts
}

\author{
FELIX K. AMEKA AND STEPHEN C. LEVINSON
}

\section{The linguistic interest of positional verbs}

This special issue is devoted to a relatively neglected topic in linguistics, namely the verbal component of locative statements. English tends, of course, to use a simple copula in utterances like "The cup is on the table", but many languages, perhaps as many as half of the world's languages, have a set of alternate verbs, or alternate verbal affixes, which contrast in this slot.' Often these are classificatory verbs of 'sitting', 'standing' and 'lying'. For this reason, perhaps, Aristotle listed position among his basic ("noncomposite") categories:

Expressions which are in no way composite signify substance, quantity, quality, relation, place, time, position, state, action, or affection. To sketch my meaning roughly, examples of substance are 'man' or 'the horse', of quantity, such terms as 'two cubits long' or 'three cubits long', of quality, such attributes as 'white', 'grammatical'. 'Double', 'half', 'greater', fall under the category of relation; 'in the market place', 'in the Lyceum', under that of place; 'yesterday', 'last year', under that of time. 'Lying', 'sitting', are terms indicating position, 'shod', 'armed', state; 'to lance', 'to cauterize', action; 'to be lanced', 'to be cauterized', affection. (Aristotle: Categories: Part 4) [emphasis added FKA and SCL]

At their most exuberant (and good examples can be found in the papers in this issue), these systems of contrasting verbs clearly impose some kind of categorization on their arguments, and thus on the world. Let us illustrate with an example. In the Papuan language Yélî Dnye (Levinson 2000b, 2006: 173-183), there are a set of just three verbs, "sit", "stand" and "hang", which effectively classify both abstract and concrete nominal concepts, according to which verb they take in both existential and locative statements. There is no copula, and no way to avoid such a choice. You simply have to know that the sun 'sits', but stars 'stand', or hunger 'hangs' while sleep 'sits', or steam 'stands' while smoke 'hangs'. Even for animates, things are not straightforward, humans canonically 'sit', but most other animals 'stand'. What if the human is standing? Then of 
course he can be described as 'standing' — and this flexibility of use is typical of such positional verbs. So how do we know what the canonical (unmarked, basic) collocation is? For novel objects there is an algorithm based on physical properties, showing that the system is semantically based, and not a grammatical classification of nouns (Levinson 2006: 179). But, in general, if you try to formulate a negative existential like "There are no humans on that island", the 'sit' verb has to be used, and this trick will establish the default collocations for all other nominals too. Although the details differ from language to language, the idea of some kind of default collocation with pragmatically-induced variation seems generally to hold.

This example shows that the semantics of such verbs, and indeed the pragmatics of their nondefault collocations, are nontrivial. One might dismiss these collocational facts as some of the minor irrationalities that languages impose on their speakers, and which make second languages so hard to learn (for such systems rarely match even across closely related languages: see Newman 2002). But in fact these semantic parameters show up elsewhere in the linguistic system. For example, in Yélî Dnye, there are other sets of (underived, independent) triplet verbs that correspond semantically to the three positionals: verbs of internal action ('stand up', 'sit down', 'make oneself hang'), verbs of putting ('put standing', 'put sitting', 'put hanging') and verbs of taking ('take a sitting thing', 'take a standing thing', 'take a hanging thing') (Levinson forthcoming). They even seem to show up in gestures when talking of e.g., putting and taking things. So there is reason to think that the categorization that these verbs impose has cognitive consequences.

The Yélî Dnye verbs form a special word class which suppletes on subject number and tense, although they otherwise do not seem to have widespread grammatical repercussions. But in many languages these verbs have taken on a grammatical life of their own. For example, in Goemai (Hellwig 2003) the positional verbs are grammaticalized in demonstratives and presentatives, resultative serializations, and progressive aspect constructions. These kinds of grammaticalizations have been one main reason that these contrastive locative verbs have been studied in the past (see the next section). Our interest here is in the synchronic patterning of these locative verbs, and in particular on the semantic contrasts they make.

One special reason to be interested in these verbs is that their role in the semantics of locative expressions has been largely ignored. Take the example of the influential article by Landau and Jackendoff (1993), in which it is argued that there is a fundamental distinction in the semantics of object names and locations - object names reflect detailed geometric 
properties of objects (so that e.g., a cup and a mug have similar functions but different shapes), while locational expressions are schematic in character, abstracting away from object shape (similar ideas can be found in Talmy 2000). Landau and Jackendoff relate this opposition to the two neural pathways known as the "what" and "where" systems (Ungerleider and Mishkin 1982), suggesting that language reflects this neurocognitive distinction. They base their linguistic generalizations on an analysis of English spatial prepositions, arguing (true enough for English) that this is where the spatial information is.

If one looks at other languages, one finds that spatial adpositions are not always so bleached of precise content about Figure and Ground as English prepositions are. For example, Yélî Dnye has a postposition, 'nedê, glossed as 'attached by spiking', which presupposes a scenario (given an expression of the form: Y X-'nede positional) where $\mathrm{Y}$ is some relatively soft material pierced by some sharp instrument which also pierces the Ground X, thus attaching X to Y (see Levinson and Meira 2003 for explorations in the crosslinguistic semantics of spatial adpositions).

But many languages depart from these English-based expectations in more fundamental ways, by having a full set of contrastive locative verbs, which sometimes specify the nature of Figure and Ground in even more precise detail. For example, the Mayan language Tzeltal has amongst its 200 odd positional verbs, the predicates pachal meaning something like 'be located (of hemispherical container), or be located in hemispherical container' and mochol 'being located (of animal lying curved on its side)' (Brown 1994). Since there is just one noncontrastive preposition, all the spatial information in this language is in the predicate. Again, the absence of a copula forces a choice between these many contrastive predicates. Systems of this kind clearly break the Landau and Jackendoff or Talmy expectations about spatial language.

In this section, we have tried to motivate the interest of these contrastive locative verbs - they are interesting from semantic, cognitive and grammatical points of view. The examples given, though, turn out to be only some kinds of locative verb. And this raises the question of the typological variation of these kinds of contrastive locative verbs in the languages of the world, to which we turn in a later section.

\section{Prior work on positional verbs}

Most prior work on contrastive locative verbs has been from a languagespecific, a familial or an areal point of view. Because of their obvious centrality in the workings of languages, contrastive spatial predicates 
usually receive some attention in descriptive grammars. But these accounts rarely give us more than the briefest sketch of the underlying semantic distinctions involved, and often neglect even the grammatical ramifications of these systems. The Americas however are something of an exception in that there are both relatively good language specific descriptions of the phenomena and areal surveys. For example, it is wellknown that Athabaskan languages like Navajo have elaborate sets of argument-classifying verbs, based on detailed semantic categories, but also that throughout North America there are many languages with 'sit', 'stand', 'lie' oppositions obligatory in locative descriptions (Watkins 1976; Mithun 1999: 106-117). Similarly, the Mesoamerican language area has a 'shape' preoccupation, which is reflected in body part calques and various systems of contrastive locative verbs (Campbell et al. 1986; de Léon and Levinson 1992). The Mayan languages, for example, have a morphological class of positional verbs, which sometimes number in the hundreds (Brown 1994; Bohnemeyer and Brown this issue), and can be recognized in Mayan hieroglyphics: these make very fine discriminations of shape, posture, and position, which are quite different in kind to the simpler 'sit', 'stand', 'lie' systems. Outside the Americas, discussion is mostly confined to the regional specialists - for example, every Australianist knows that Pama-Nyungan languages mostly have a "sit", "stand", "lie" opposition, but the handbooks hardly mention this (see, however, Goddard and Harkins 2002; Reid 2002). Similar remarks probably hold for many other regions.

For African languages also, grammars are rather silent on the topic, or when they do mention these verbs they focus not on their locative function or semantics but on how the lexical items function in the grammars. Not until the work of Keegan $(1997,2002)$ on Mbay, a Nilo-Saharan language spoken in Chad, do we get an indication that African languages also use postural verbs to code the basic locative function. The most detailed study to date of an African language in this domain is that of Hellwig (2003) on Goemai, a Chadic language of Nigeria (see also Hellwig this issue). There are informal suggestions that other languages such as the Gur language, Gurene, of Ghana also uses posture verbs in locative constructions (Samuel Atintono p.c.).

One major collection of articles appeared in Newman 2002. This focuses on the human posture verbs 'sit', 'stand' and 'lie', on their anthropocentric origin, the extensions of their meanings based on that origin, and their tendency to grammaticalize into locative verbs and eventually aspect markers. While these papers, which give much detail on a dozen languages and more sketchy information on more, are very valuable, they do not provide the close comparison of meanings and functions that 
this special issue makes available. Further, they are restricted to just one type of positional, derived directly from human postural verbs. But to return to the example of Yélî Dnye, this language, which opposes 'sit', 'stand' and 'hang' verbs, already does not fit this anthropomorphic theme (things that 'hang' are bags, ropes, bats, and strips like trails and rivers, etc., but rarely humans). And once we turn to languages with more oppositions, we leave the anthropomorphic mould far behind.

What makes the present collection special is that all the authors undertook concerted fieldwork, specially commissioned, using the same detailed checklist of features to look for, and most important, an identical set of stimuli specially designed to explore the application of locative verbs to varied scenarios, with different objects, in different numbers and arrangements, in relation to different supports or Ground objects. These stimuli sets are described below.

\section{Setting up the present project}

\subsection{The typological predictions}

The Language and Cognition Group at the Max Planck Institute for Psycholinguistics has investigated spatial description in a wide range of languages (see Levinson 2003; Levinson and Wilkins 2006). We early observed the following sorts of tendencies:

In English relative location information is almost entirely packaged in the prepositional phrase with a vacuous locative verb be fulfilling the need for a (tensebearing) predicate. But many languages have a set of contrasting locative verbs. Thus whereas in English we indiscriminately use locative be in The book/cup is on the table or The key is in the lock, or The picture is on the wall, in German we must say Das Buch liegt auf dem Tisch, Die Tasse steht auf dem Tisch, Das Bild hängt an der Wand and Der Schlüssel steckt in dem Schloss, the distinctions encoding geometric properties of the Figure (whether the object is flat or has a canonical base etc.) or the Ground (whether it is a container, a vertical surface, etc.) or of the relation between them. Some languages carry such distinctions to the extreme: thus Tzeltal forces a choice between over one hundred commonly used locative predicates, each of which encodes especially properties of the Figure object (shape, disposition, angle etc.) or occasionally of the Ground or the relation between Figure and Ground. This then takes the burden of locative description off the adpositional phrase - in Tzeltal there is a vacuous preposition corresponding to the English vacuous locative verb. (Levinson 1992: 29)

As good usage data from various languages like Yélî Dnye and Tzeltal became available, we developed this incipient typology into a quite 
extended set of generalizations and predictions. We present these at three levels in the schemas in (1), (4), (5), (6) and (7) with attendant discussion. Since we shared these predictions with the authors of the papers in this issue and asked them to check many aspects of these predictions, we need to repeat the details here. But the reader should be forewarned that not all the predictions have been confirmed.

The original hypothesis about the main types of locative construction in the worlds' languages is presented in (1). ${ }^{2}$ At a gross level, this is nothing more than a count of the number of contrasting locative verbs in a language: none, one, around three to five, six or more. But such an account actually relies on a clear context of use. Three kinds of difficulties immediately appear.

(1) Four basic types of locative predication in an unmarked locative statement

Type 0: $\quad$ No verb in basic locative construction: Saliba

Type I: $\quad$ Single locative verb (or suppletion under grammatical conditioning)

Type Ia: Copula (i.e., dummy verb used in many other constructions): English, German, Tamil Locative/existential predicate: Yucatec

Type Ib: Locative verb determined by grammatical categories: Japanese, Chinese (Turkish)

Type II: Large or unlimited set of positional verbs: Likpe, Tzeltal, Zapotec

Type III: Small, contrastive set of Posture or Positional verbs: Guugu Yimithirr, Rossel, Dutch, Arrernte

The first difficulty concerns stylistic variation. For example, in English it is entirely natural to say The cathedral stands in the heart of the old city, as can be verified in any guidebook. However, it would not be colloquial, in response to a where-question like Where is the cathedral? to respond it stands in the heart of the old city, as opposed to something like it's in the centre of town. We call this latter use, in the context of a where-question, the BASIC LOCATIVE CONSTRUCTION (BLC) (see Levinson and Wilkins 2006: 15-17 for more detail), and all the generalizations we make here (and most in the papers below) hold for this particular kind of language usage. The BLC is typified by a distinctive set of locative verbs(s), and an oblique NP indicating the Location (obliqueness marked by adposition, case, adverbializer). ${ }^{3}$ Where two or more constructions might be candidates for identification as the BLC, we recommended to our authors that they examine how they were used to describe stereotypical vs. exceptional scenes, which construction was used in negative 
I Piercing

II Firm attachment/encirclement

III Negative space

IV Part/whole

V Clothing/adornment

VI Moveable objects

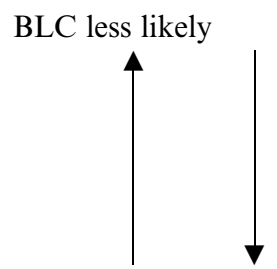

More likely BLC encoding

Figure 1. Basic locative construction or localizability hierarchy

locative statements, and the frequency of use in the stimuli descriptions we asked for.

A second difficulty is that even when there is a clear intuition that a particular construction is the basic locative construction, there will be many occasions where it will not be used for more systemic reasons. For example, it is frequently found that languages will not use a locative construction at all to describe a ring on a finger, or a paper skewed on a nail - many languages here call for a resultative construction of some sort. We proposed, following ideas of David Wilkins, a hierarchy of situation types in which the BLC was more - or inversely less - likely to be used (see Levinson and Wilkins 2006: 15-17, 514-519). In the hierarchy (Figure 1), a small, manipulatable, freely moveable item on or in a restricted surface or space was hypothesized to be the most likely kind of scene to get coded with the BLC. In contrast, items attached by piercing or encircling were thought to be the least likely scenes to be so coded, because other constructions (like resultatives) would invade this end of the continuum. With such a crosslinguistic generalization, then, one can still hold on to the notion of a BLC even in a language where many scenes are coded otherwise. One of the outcomes of this project is that this hierarchy in fact needs some revision (see Section 4).

The third difficulty concerns distinguishing full from elliptical constructions. Many languages permit locative structures without verbs, e.g., in Tamil the BLC has an optional BE-verb (which is obligatory in the existential) with an obligatory oblique NP (case marked, +/- postposition). Very natural then would be the following exchange:

(2) a. Ramu enke?

Ramu where

'where is Ramu'

b. Ramu tooTTattile (irukkiratu)

Ramu garden-LOC

'Ramu is in the garden' 
One has to decide then whether the copula is the core construction, with pragmatic reduction, or not. Where we have quantitative data, it doesn't always help us decide. For example, the Australian language Guugu Yimithirr has a 'sit', 'stand', 'lie' opposition available, but when one of the stimuli sets described below (TRPS) was described, we obtained the following results (Levinson unpublished data):

$\begin{array}{ll}\text { (3) Positional verbs } & 45 \% \text { of stimuli } \\ \text { No verb } & 41 \% \\ \text { Other construction } & 14 \%\end{array}$

The decision has to be made (a) on the basis of whether a verb is available for colloquial use, (b) on a sense of whether using a verb communicates a marked message or unusual scenario (as would be expected if the no-verb utterance is basic - see Levinson 2000a for the pragmatic theory here).

With these two restrictions, the typology in (1) seems to "bite". A couple of further points, though, need to be made. First, as far as we know, each of the four types of locative expression may or may not, according to language, be shared by the existential construction in that language. This dovetails with Clark's (1978) typological generalization that two thirds of languages tend to use the same verbs in both the locative and existential constructions.

Second, as far as we know, all languages have human posture verbs, i.e., verbs of the kind 'sit', 'stand', 'lie', 'squat', 'kneel', etc. (Not all have the same semantic inventory as our own verbs - Yélî Dnye for example does not have a verb of lying.) But their role in these systems is various. Many postural verbs have no extended locative uses ('kneel', 'squat' may be such verbal notions with little locative appeal). Nevertheless, many human postural verbs often play, or have in the past played, a crucial role in the system of locative verbs. They may often be the diachronic source for currently bleached copulas (as is true for many Indo-European copulas). There are likely to be some human posture verbs in the Type II "large set" positional verbs, while in the Type III or "small set" positional verbs they are often the principal (see Newman 2002) but often not the only source (as in Yélî Dnye 'hang'). Why the prevalence of human posture notions in location statements? A plausible hypothesis is that there are two kinds of basic strategy for indicating where things are: (a) say where it is, (b) say what it looks like, so the inquirer can find it. The languages that go to great lengths to indicate shape and postural configuration, such as the Type II languages like Tzeltal, often have weak directional specifications - e.g., in Tzeltal only one preposition. Human posture is one natural metaphor for shape configuration. The degree to 
which human postures are generalized to cover inanimate subjects seems related to the type of system: a generalization we call "Ameka's conjecture" is that the further down the types one goes, from Type I to Type II to Type III, the more likely it is that inanimates will collocate with human posture verbs. ${ }^{4}$

Let us now say a little bit about each of these types of locative predicate. The hypotheses we had developed for each type of locative on the basis of limited languages in advance of the project are presented in summary form in (4)-(7), followed by a text explaining these in more detail.

(4) Type 0 (verbless) locative constructions - some predictions

1. Although languages may have this as the most frequent form of the locative, no language has a verbless construction as the exclusive means of locative statements - that is, a verbal form always competes (cf. Stassen 1997: 585-586);

2. Where a verbless structure competes with a "verby" one, the verbless structure will be favored in descriptions of stereotypical situations (Levinson's pragmatic prediction 2000a, 2000b);

3. Languages which favor unmarked Ground nominals (no case or adposition) will not permit verb deletion (otherwise no marker of locativeness will be left). Languages which do not allow locative verb deletion will in certain stereotypical circumstances allow contraction of the Ground phrase, e.g., adposition/locative-case deletion (Dutch thuis 'at home'), article deletion (English at school), etc. (Levinson's pragmatic prediction 2000a).

Our predictions over languages with verbless locatives are outlined in (4). Stassen (1997: 233ff) suggests that these may not occur at all — that is, that any verbless construction would always alternate with a verbal predicate construction (cf. the facts for Guugu Yimithirr and Tamil above). The rest of the predictions suggest that any verbless strategy will contrast pragmatically with a verbal one, and that the way the Ground is marked may affect the possibilities of verb deletion.

Our expectations about single-verb locative constructions are outlined in (5). (Recollect that we include here languages with more than one verb if the choice of verb is determined by grammatical categories rather than shape or spatial properties.) These were not the focus of the present project, but issues quickly arose concerning, for example, the use of postural positionals in German which are quite far-reaching, but yet do not have the obligatory character of such positionals in Dutch. For in German the positionals compete with the copula sein, along the lines 
sketched in point 4 in (5) (we owe this general hypothesis to Jürgen Bohnemeyer). One is thus unable to study the use of positionals in many languages without considering the competition between the single verb strategy and the multiverb strategy.

(5) Type I locatives with a single locative verb - some predictions

1. This is perhaps a minority strategy in the languages of the world;

2. Single locative verbs often extend their functions to become support verbs for nominal and adjectival predications, i.e., become copulas;

3. Single locative verbs and copulas often derive diachronically from postural or positional verbs (e.g., estar from *sta- 'stand'), drawing their suppletive stems from the older set of verbs;

4. Such single locative predicates may often be under pressure from extended uses of human posturals, with postural positionals invading the following hierarchy of Figure objects in locative constructions, from the animate end - thus offering an effective division of labor as in German:

Figural hierarchy

animates $>$ free objects on surfaces $>$ contained objects $>$

attached objects

Postural verbs-

Copula

We come now to the heart of the current enterprise, which is the contrast between languages with a small set of positionals (often drawn from the human postural verbs) and the languages with large sets of descriptive positionals which are de rigueur in locative expressions. On the basis of earlier work, we had noted a number of contrasts, which are summarized in (6) and (7).

For the languages with multiple (six or more) verbs in opposition, we had the Mayan languages in mind (see, e.g., Brown 1994) as our prototype, and had made rather detailed predictions about their properties as in (6). We suggested that specific linguistic ecologies motivate these systems, namely nominal semantics lacking individuation, and the lack of a developed adpositional system making topological spatial contrasts. As general characteristics we suggested that these systems therefore contained very specific information about the properties of the Figure object (the subject of the clause) and had an assertional force about the current shape/disposition of the Figure. 
(6) Type II: languages with large sets of contrastive locative verbs ("dispositionals")

1. One general verb, or another verb like an existential predicate, can be used if none of the more specific dispositional verbs is relevant (as in "What's in the cupboard?"). The general verb may be deployed more with abstract nominals, location in large scale space, marked tenses and aspects;

2. Some dozen of these dispositional predicates are frequent and may have a distinct status (this may mirror the sortal vs. mensural distinction in classifiers);

3. The use of these dispositional verbs is motivated by other factors in the linguistic system, especially:

(a) "Mass"-type semantics for "middle-range" nominals (i.e., nominals that refer neither to undifferentiated substances like water, sand; nor to self-individuating, mobile entities like animals). Thus given a masslike noun, e.g., 'banana', a dispositional can signal whether we are talking about banana leaves, stems or fruits

(b) Lack of a large contrastive set of adpositions or local cases, requiring topological spatial information to be signaled in the verb;

4. The use of one of these verbs asserts rather than presupposes that the Figure object currently has the disposition described. The verb is therefore nonomissible and more in focus (and thus more stressable, more gesturable) than the copula or small-set positionals in other languages;

5. The semantics of these verbs is often very detailed and language specific, but the dimensions involved are likely to include:

(a) canonical vs. noncanonical position (e.g., upright vs. nonupright, relevant e.g., to containers)

(b) for flexible, articulated objects, how flexed or folded

(c) volumetric and axial properties of objects (e.g., 1D vs. 2D vs. $3 \mathrm{D}$, solids vs. containers)

(d) single vs. multiple or mass Figures - i.e., whether the Figure object is individuated

Lastly, turning to the small-set positional verb languages, and using languages like Yélî Dnye as prototypes, (7) makes clear that we foresaw that these have some similarities with the large-set locative verbs, but also many detailed points of contrast. Many of these suggested contrasts have been corroborated in one language which has both systems! This language is Goemai, which allows both systems to coexist by restricting the 
Table 1. The expected contrast between small-set and large-set positional verb languages

\begin{tabular}{|c|c|c|}
\hline & Small-set positionals & Large-set dispositionals \\
\hline Number of verbs & $3-5$ & $9-200$ \\
\hline $\begin{array}{l}\text { Role of human } \\
\text { posture verbs }\end{array}$ & central & marginal \\
\hline Motivation & $\begin{array}{l}\text { disambiguation of general } \\
\text { nominals may play a role }\end{array}$ & $\begin{array}{l}\text { masslike nominals, lack of rich } \\
\text { adpositions }\end{array}$ \\
\hline Semantic character & $\begin{array}{l}\text { abstract axial/geometric } \\
\text { properties, with some } \\
\text { functional aspects }\end{array}$ & $\begin{array}{l}\text { much more detailed properties } \\
\text { of figure object, using } \\
\text { language-specific } \\
\text { discriminations }\end{array}$ \\
\hline $\begin{array}{l}\text { Truth-conditional } \\
\text { character }\end{array}$ & $\begin{array}{l}\text { not necessarily false if predicate } \\
\text { does not literally apply }\end{array}$ & false if predicate does not apply \\
\hline Usage character & $\begin{array}{l}\text { default use presupposes rather } \\
\text { than asserts properties of figure }\end{array}$ & asserts properties of the figure \\
\hline Syntactic character & $\begin{array}{l}\text { well-defined form class, often } \\
\text { with lexicalized causative } \\
\text { counterparts; can sometimes be } \\
\text { elided }\end{array}$ & $\begin{array}{l}\text { form class, with less clear } \\
\text { boundaries; cannot be elided }\end{array}$ \\
\hline Classifying role & $\begin{array}{l}\text { verbal sortal classification of } \\
\text { nominal concepts }\end{array}$ & describe current situation \\
\hline
\end{tabular}

two systems to different ecologies (Hellwig 2003). In tabular form, the expected contrasts between the two kinds of system can be represented as in Table 1.

(7) Type III: languages with small sets (3-5) of contrastive locative verbs

1. As with large-set locative verb systems, one more general verb, or another verb like an existential predicate, can be used if none of the more specific positional verbs is relevant (as in "What's in the cupboard?"). The general verb may be deployed more with abstract nominals, location in large scale space, marked tenses and aspects;

2. The presence of such a set of contrastive locative verbs may be encouraged by, but is not dependent on, other features of the language - for example, a range of semantically general nouns (e.g., 'wood/fire', 'river/water', 'tree species/fruit'), which can be usefully disambiguated by positionals and classifiers;

3. These verbs typically draw on the human posture verbs 'sit', 'stand', 'lie', but often also incorporate less anthropomorphic positionals like 'hang';

4. They are likely to have causative counterparts, i.e., a contrastive set of putting verbs distinguished by the nature of 
the object being placed, and they may also have a set of parallel 'taking' verbs;

5. Despite the partially anthropomorphic source, the usage of the verbs is partially or even largely determined by abstract geometric properties of the Figure object (the subject of the verb). For example, for physical objects, this is likely to be based on the orientation of the maximum axis of the object when in canonical position (i.e., the position in which an object normally occurs, is used, or stored) - perhaps generally: 'stand' - when long axis is canonically vertical 'lie' - when long axis is canonically horizontal 'sit' - when there is no major axis, or object has a wide base in canonical position 'hang' - when not supported from below.

As this suggests, the 'sit' verb is likely to be the default verb or residual category (contrary to the 'stand' prediction in Newman 2002) - the form to be employed e.g., in "What did you say is _ on the table?" Functional factors, like having a base, are also likely to be important. For abstract nominals there are likely to be collocational conventions, perhaps according to some cultural logic;

6. These verbs, forming a minor form class, have a sortal character, i.e., they "classify" their subject nominal concepts by semantic criteria, and thus constitute a kind of nominal classification;

7. What is classified is not the noun, and not primarily the referent, but rather the "nominal concept" - thus the addition of individuating classifiers or quantifiers may alter the choice of verb;

8. Such positional verbs typically have two uses, a presuppositional use vs. an assertional use:

(a) the presuppositional use is given by a default collocation of nominal concept and positional, either by convention, or in the case of physical objects by their canonical position according to the stereotypical orientation of axes. The test for the default collocation is use in negative locatives (or if the language here uses the same construction, in negative existentials): If, when you want to deny that the bottles are on the table you have to say "The bottles are not standing on the table", then bottles 'stand' by default.

(b) The assertional use usually involves a choice of some positional other than the default (e.g., "The bottle is lying 
on the table"), and asserts a noncanonical position for a physical object.

In the presuppositional use, one asserts location and "presupposes" orientation; in the assertional use one asserts orientation, and (perhaps) presupposes location. It follows that in most of these languages it will not be false in answer to a Where question to say the equivalent of "The bottles are standing on the table" even if one of them is lying on its side.

\subsection{The methods employed: the stimuli and their construction}

Our survey of earlier work, with its relative neglect of contrastive locative predicates, and the theoretical speculations developed in the prior section, motivated the collection of in-depth data from a wider range of languages. It was clear that what was really lacking in earlier accounts, and also crucial to building typological generalizations of the kind above, was good data on the semantics of the different kinds of verbs. The area seemed ripe for what has come to be called the "Nijmegen method" the collection of data directly in the field using standardized stimuli that cover a shared extensional grid, allowing close and accurate comparisons of semantic distinctions. To this end, we encouraged researchers to collect data using two elicitation tools in particular:

(i) The Topological Relations Picture Series (TRPS) also referred to as BowPed (after the principal designers Melissa Bowerman and Eric Pederson) or as the "yellow book". TRPS is a book of 71 line drawings. Each picture shows principally two objects, one of which is identified as the Figure object (by being colored appropriately, or designated by an arrow), the other the Ground. The investigator shows e.g., a picture of a cup on a table and asks where the Figure is (e.g., "Where is the cup"), expecting an answer that locates the Figure with respect to the Ground (e.g., "The cup is on the table"). Where the picture is culturally inappropriate, the researcher is expected to find a parallel appropriate scenario (e.g., a gourd on a chair) and ask about that instead. The answers are recorded and transcribed, and a good range of consultants asked to do the same task.

The TRPS was originally designed to investigate the maximal range of scenes that may be assimilated to IN- and ON-relations, but includes a good range of other scenes that are not likely to be so assimilated. Pictures depict e.g., a cup on table (Picture 1), or a lamp above table (Picture 13) or a ball under chair (Picture 16), 


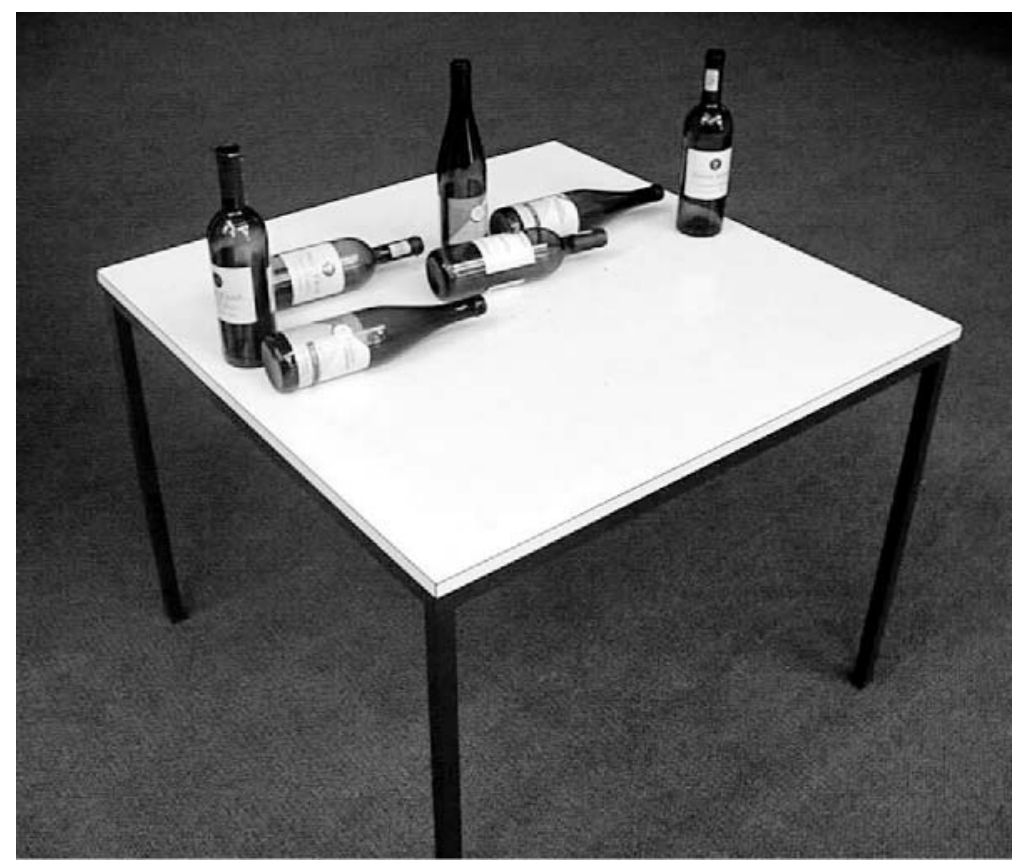

Figure 2. Three bottles standing and four lying on table top (PSPV 46)

and so forth. The full set is published in Levinson and Wilkins (2006: 570-574), but is also available from the Max Planck Institute for Psycholinguistics website (www.mpi.nl).

(ii) The Picture Series for Positional Verbs (PSPV) designed by the editors with help from other colleagues (also known as the "orange" or "red book"). This book of 68 photos was specifically designed to illuminate the hypotheses outlined in the prior section. Nine different Figure objects (stick, ribbon, cloth, rope, cassava, bottle, ball, beans, pot), in singles or multiples, were placed in relation to seven different Grounds (table, tree branch, tree stump, tree trunk, basket, rock, earth) in various positions (canonical vs. noncanonical). The full set of permutations would have been too large a set, but the chosen set included a good sampling of the possibility space, with a specific eye on the hypotheses in the prior section. For example, picture 46, shown in Figure 2, has three bottles standing and four lying on a table top, whereas another, picture 52, shown in Figure 3, has all seven lying. It was expected that, while both large-set positional and small-set positional 


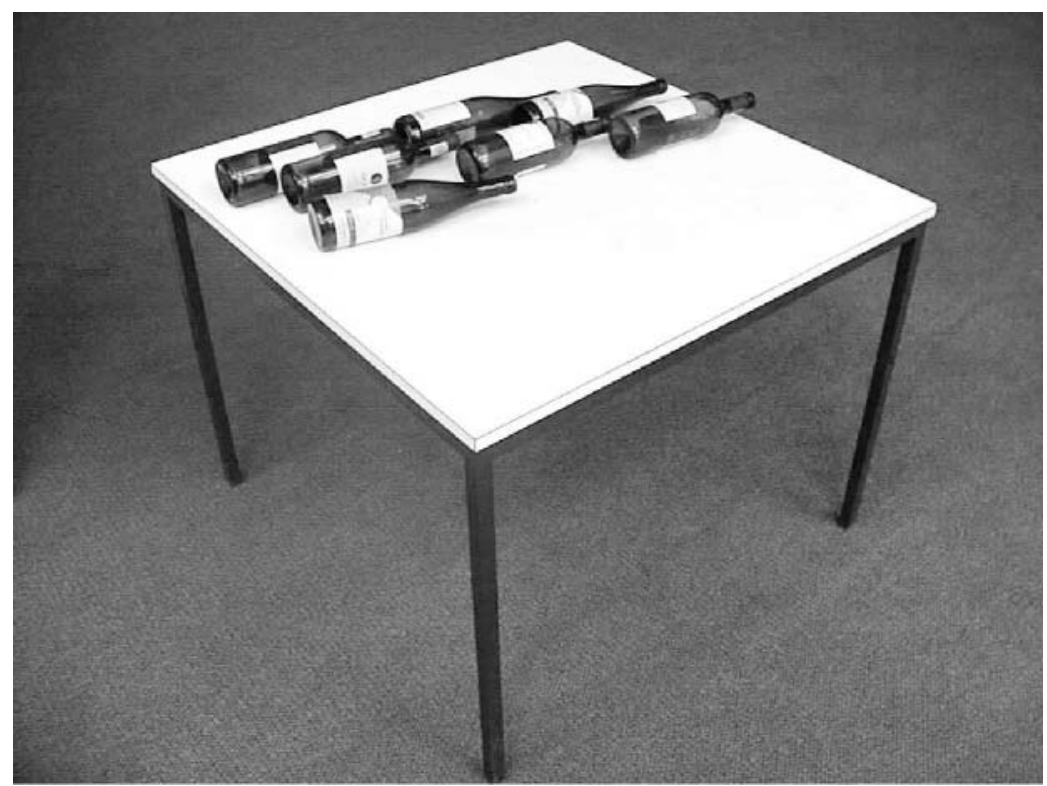

Figure 3. Seven bottles lying on table top (PSPV 52)

languages would describe Figure 3 with a 'lying' verb, some smallset positional verb languages would permit Figure 2 to be described solely with a 'stand' verb, while no large-set positional verb language would permit this. This proves to be true for e.g., Yélî Dnye (as small-set language) and Tzeltal (a large set one). The full set of photos is available from the Max Planck Institute for Psycholinguistics Web site (www.mpi.nl).

All the contributions to this issue are based on first-hand field investigations utilizing these elicitation tools. The elicitations are supplemented by other extensive investigations including field-site specific stimuli as well as examination of text corpora to provide additional validation for the focused elicitation.

\section{The results - what the papers show}

The studies reported on in this special issue show that the typology of locative predication presented in (1) is valid, but like any categorization there is the need to sharpen the membership structure of each type. 
Some modifications are thus needed: One "cosmetic" modification was already implemented before some of the papers were finalized. Recall that the typology is based on the number and the semantic type of predicates used in the BLC. The labeling of the Types was modified to make it a bit more iconic with the size of the number of verbs. Thus the ordering of the "small set" and "large set" or multi verb types is reversed. The former becoming Type II and the latter Type III, as reported in Kelly and Melinger (2001: 63), shown here in (8). A second modification relates to the naming of the Types according to the "semantics" of the verbs. The small set type has been called "postural" or "positional" while the multiverb type has also been called "positional" or "dispositional". The terminology thus differs slightly across papers (in part conforming to areal linguistic traditions), but each paper is consistent in terms of the labeling system used.

One result of the studies presented is that the small type and multiverb type should also be subdivided the way Type I is to reflect the semantic types of verbs. In terms of number of predicates in the BLC, Tidore, a Western Papuan outlier spoken in the North Moluccas of Indonesia, with its seven locational verbs in the BLC could be typologized as a small-set type language. However, the verbs are not postural, rather they express the Ground space in which the Figure can be found (van Staden this issue). Tidore further provides evidence for a distinction between a small-set type and a multiverb type as it has in addition to the seven Ground space indicating locational verbs, twenty or so dispositional and configurational verbs. The latter are used in noncanonical contexts. Similarly, Goemai, a Chadic language of Nigeria, furnishes language internal evidence for the small set (postural) and multiverb types, where the former can be used presuppositionally while the latter are used assertionally as had been predicted for the two types (Hellwig 2003, this issue).

(8) Four basic types of locative predication (modifications) (languages discussed in the contributions are italicized).

Type 0: $\quad$ No verb in basic locative construction (Saliba, Austronesian, Papua New Guinea)

Type I: $\quad$ Single locative verb (or suppletion under grammatical conditioning)

Ia: Copula

(i.e., dummy verbs used in many other constructions;

English, Tamil, Chukchi, Tiriyó)

Ib: Locative (+Existential) verb

(Japanese, Ewe, Yukatek, Lavukaleve) 
Type II: A small contrastive set of locative verbs (3-7 verbs)

IIa: Postural verbs

(Arrernte, Dutch, Goemai)

IIb: Ground space indicating verbs

(Tidore)

Type III: Multiverb Positional verbs (a large set of dispositional verbs, 9-100) (Tzeltal, Zapotec, German Laz, Likpe)

This typology is supported by the fact that genetically, typologically and areally related languages belong to different types in terms of locative predication. As amply demonstrated by Bohnemeyer and Brown (this issue), the two Mayan languages Tzeltal and Yukatek despite being genetically and typologically endowed with similar structures including a large class of positionals, use these resources differently. Yukatek is (or has become) a single-verb type language that uses an existential as the predicate in the BLC. Similarly, the closely related Germanic languages, Dutch and German, belong to two different types. Dutch belongs to the small-set type that uses six verbs in its BLC (see van Staden et al. (2006), who tested some of the hypotheses in relation to Dutch). German, on the other hand, as Kutscher and Schultze-Berndt (this issue) show, is a multiverb language using 10 verbs in its BLC. These authors also allude to the fact that dialects of the same language may diverge in terms of the different sets of verbs they deploy in the BLC.

The robustness of the usage typology is also borne out by the diachronic dimension. It has been known for some time that posturals develop into copulas and for many languages this could have meant a shift from the small set type to a single verb type. Impressionistically, German is sometimes thought of in such terms, but in fact it appears that it has moved from the Germanic postural type to a multiverb type. The types are thus targets for the outcome of linguistic change processes, and consequently it is sometimes hard to attribute a language to a single type. For example, as Guirardello-Damian (this issue) shows, Trumai, a Brazilian language, is a Type Ia single verb language that uses a general copula with the option of a zero copula in its BLC. However, it is developing into a small verb-set type of language where six postural verbs are also used in answers to "where-search" questions. That is they are being used in constructions that express the basic locative function. Both construction types, copular and postural seem to be used equally and preferences are not clear at this stage. As Guirardello-Damian stresses, the language is currently somewhere between a Type Ia general copula language and a small-set type language. It may not be long before the change is complete 
and the copular verb becomes a default verb in a small-set system (as our predictions suggest).

In general, the number-of-predicates part of the typology represents targets towards which languages may develop, even if the semantics do not completely coincide with expectations. As Ameka (this issue) shows, Likpe uses 15 verbs in its BLC, while a close typological and genetic relative of Likpe, Nyagbo (James Essegbey p.c.), uses only four verbs in its BLC in comparison. From that point of view Nyagbo belongs to the small-set type but the verbs involved are 'be.on', 'be.in', 'be.at' and 'hang'. Only the last one is postural in a sense. Such a language probably belongs to a configurational verb subtype of the small-set languages (a Type IIc).

We now turn to how the predictions for the different types of languages fared in the studies. By and large, the predictions for the small-set and multiverb types are borne out (as in [6], [7] and Table 1). Thus all the languages reported on here which belong to these types have a general residual verb as a member of the form class. Goemai (small-set) deploys an existential verb for this purpose. German (multiverb) uses a copula while Laz (multiverb) has a locative copula as the general default verb but also uses a 'lie' verb as a residual verb in some contexts. Similarly, Likpe (multiverb) divides the labor of the general verb among three basic topological verbs: a 'be.in', 'be.at', and a 'be.on' verb. As already mentioned, Tzeltal (a large-set language) uses an existential verb as a residual category verb. Predictions 2 and 3 for multiverb languages (in [6]) are more applicable to Tzeltal than to the other multiverb languages discussed in this issue. Prediction 2 concerns the fact that a subset of the verbs, say a dozen or so, are more frequent and have a special status. Apart from Tzeltal, for the other multiverb languages discussed here - German, Laz and Likpe the number of verbs ranges from 10-15, yet there are subclasses that seem more frequent and have a distinct status, as for instance the basic topological verbs in Likpe. Prediction 3 suggests that the multiverb languages are likely to have "masslike" nouns. This is true of Tzeltal but not the other languages. The second part of the prediction says that these languages lack a large contrastive set of relational adpositions or local cases. This is true of Tzeltal, Likpe and Laz. However German does have a sizeable adpositional class. But this feature of German can be explained on the basis of it being more like the small set type languages in this regard.

German is the exception to part of prediction 4 in (6). In all the multiverb languages the verbs assert rather than presuppose the current location of the Figure. This is also true of Goemai's second class of dispositionals in contrast to the postural verbs in that language. Because of this 
assertive use it was predicted that the verbs in the BLC of multiverb languages cannot be omitted. This is the case for all the multiverb languages studied in this issue except German where the verbs can be omitted. In this, German behaves again like the small set postural type languages. For each of the multiverb languages, the studies provide detailed semantics of each of the verbs. For Laz and German, the authors include flow charts that show the principles that determine the choice of the verbs.

The predictions for the small-set type languages of the postural type are also borne out by Goemai and also Trumai, which is not yet a full member of this set (see [7]). In fact prediction 3 in (7) can be more forcefully stated: the languages draw on human posture verbs but always include nonhuman ones also such as 'hang'. Goemai shows that the causative counterparts of the verbs need not be lexical, as is the case in Dutch, but can be generated by their use in specific constructions (using, in the case of Goemai, the serial verb construction). Both for Goemai and for Trumai (an incipient small-set postural type language), the verbs classify not the referents but the concepts and have a sortal character.

The Type 0 and Type I languages reported on here were included as a control to test the limits of the other types. As Dunn et al. (this issue) show, the conjecture that such languages are less likely to use human posture verbs with inanimates is not clearly supported. The Type I languages - Tiriyó, Chukchi and Lavukaleve - show a tendency that supports the conjecture: Tiriyó does not use human posture verbs, although it uses adverbials derived from them with inanimates. Chukchi also does not use human posture verbs with inanimates. Lavukaleve, on the other hand, "allows posture verbs with inanimates but they are rare in spontaneous texts" (Dunn et al. this issue). The major challenge to the conjecture which has been dubbed Ameka's conjecture is Saliba, a Type 0 language. Posture verbs can be used with a semantically delimited set of inanimate Figures, reflecting the semantics of the posture verbs, which require Figures with a rigid base, a vertical axis or long axis, and so forth. One way to save the idea behind the conjecture is to restrict it by making it a prediction for Type I languages. These languages will be less likely to use human posture verbs; if they do then they are probably on the way to becoming small-set type languages such as Trumai. Saliba also goes against one of the universal tendencies proposed by Stassen. Stassen (1997: 56) proposes that "if a language has a unique encoding of locational predicates, that encoding will involve the use of a locative verb". However, Saliba has a single locational strategy which does not involve a locative verb. Rather it involves a nonverbal particle. Type 0 languages are thus different from Type I languages, and it is necessary to 
distinguish them, contra Grinevald (2006: 32) who collapses Type Ia and Type 0 because "neither type has a verbal element carrying spatial information".

Some pragmatic predictions were made concerning general presumptive meanings (Levinson 2000), for example prediction 2 in (4) concerning Type 0 but also potentially Type I (Where a verbless structure competes with a verby one, the verbless structure will be favored in descriptions of stereotypical situations). The condition obtains only in Tiriyo and Chukchi among the Type 0 and I languages. In both languages, however, it is not clear what the semantic and/or pragmatic difference is between the two structures. The Type I languages reported on in this issue do not favor unmarked Ground phrases. Hence the pragmatic prediction (see point 3 in [4]) that such languages would not allow verb deletion could not be tested. However, this prediction holds for a Type I language like Ewe (Kwa, West Africa), where prepositions are not used to mark the Ground phrase in the BLC (see Ameka and Essegbey 2006).

A related pragmatic prediction is that languages which do not allow locative verb deletion allow the contraction of Ground phrases. This prediction in itself is not limited to particular locative predication types, as exemplified by English and Dutch in (4). Another example of this is provided by Likpe (Ameka this issue). As predicted for multiverb languages, Likpe does not allow verb deletion. However, it allows for the deletion of the search domain-signaling postposition, especially, when such information can be inferred from the locative verb, thereby contracting the Ground phrase.

By and large the studies support the predications made at the outset in (4), (5), (6), and (7). Needless to say, these predictions still need testing against a wider sample of languages, as, for example, with the predicted contrastive alternation between verbless and verby structures in relation to stereotypical situations. There is also the need to sharpen the predictions for the small-set type languages whose verbs are not prototypically of the postural type, e.g., Tidore. More languages of these other types and of Type 0 languages should also be investigated to seal the locative predication typology.

Finally, we turn to the BLC or localizability hierarchy outlined in Figure 1 above. The major finding from the studies in this issue is that this hierarchy is not strictly linear. For some languages it works perfectly. Thus in Saliba, the Type 0 language, the BLC only applies at two levels: VI moveable objects and V clothing and adornment. Beyond this other constructions have to be used. Similarly Lavukaleve and Chukchi Type I languages also allow the use of the BLC in situations involving up to one 
level higher in the hierarchy than that in Saliba. Then they use the BLC for part-whole configurations between Figure and Ground (as in 'the handle is on the door'). For other languages discontinuities are reported. For Tiriyo, the BLC is used for levels VI, V and IV as well as for IIa firm attachment, but not for encirclement. It is also not used for negative spaces, level III. For Laz, the BLC is used for the situations at the end points of the hierarchy but not for the middle portions. Thus it is used for levels I and II and V and VI. It is not used for situations relating to part-whole (level IV) or negative spaces (level III). For Likpe also the BLC is not used for levels III (negative spaces) and V (clothing and adornment). The BLC is used in German for all levels except the encirclement one, level IIb. One can also make finer distinctions with respect to German relating to the verbs that are used. It turns out that for levels III (negative spaces) and IV (part-whole) the only verb that can fill the BLC is the copula sein 'be'. Other than that many situations are covered by the BLC. The solution is to propose a nonlinear structure for the localizable situations, which allows rival constructions to preempt different parts of the hierarchy, now conceived of more in terms of a two dimensional space as in "semantic maps".

The contributions in this special issue are aimed at bringing the verbal component in locative constructions back into descriptive and theoretical focus. What we have focused on here is languages which have sets of locative verbs in contrastive relationship to one another, where the contrasts carry spatial information. For comparative purposes there is a contribution looking at the way locative descriptions operate in languages that have no verb (e.g., Saliba) or just a single verb, in the basic locative construction, such as Lavukaleve. This is the first article. It is followed by three papers on languages with small contrastive locative verbs Goemai (Hellwig) Trumai (Guirardello-Damian) and Tidore (van Staden). While Goemai and Trumai use postural verbs, the Tidore system uses locative verbs that have frame of reference and direction semantics. Its system is in a sense orthogonal to the rest. The next three papers deal with languages which are multiverb languages: German (Kutscher and Schultze-Berndt) Laz (Kutscher and Genç) and Likpe (Ameka). The issue concludes with a comparison of two Mayan languages, Yukatek - a single verb language - and Tzeltal a multiverb language (Bohnnemeyer and Brown).

This special issue is the first one we are aware of that looks at the verbal component of locative constructions from such a wide range of typologically and genetically divergent languages using the same set of elicitation tools and testing specific hypotheses about the consequences of using particular types of verbs in the expression of the basic locative 
function, i.e., the typical and preferred full clause response to a "where" search question.

\author{
Leiden University \\ Max Planck Institute for Psycholinguistics
}

\title{
Notes
}

1. There does not seem to be any typological database offering frequencies for contrastive locative verbs. In our Island Melanesia typological database, covering Oceanic and Papuan languages, $36 \%$ of 42 languages have positionals (see Dunn et al. 2005). Correspondence address: Felix Ameka, Dept. African Languages and Cultures, Leiden University Centre for Linguistics, PB 9515, 2300 RA Leiden, The Netherlands. E-mail: f.k.ameka@let.leidenuniv.nl or felix.ameka@mpi.nl.

2. We thank David Wilkins for many ideas here.

3. Many researchers (e.g., Talmy, Jackendoff, Stassen) claim that the oblique markers tend to encode the spatial relationship of Figure to Ground, while the verb may or may not encode aspects of the positioning of the Figure (but there are notable exceptions here, e.g., Tzeltal, Brown 1994). But some languages do not mark the Location as an Oblique NP, instead using an unmarked NP with a locative verb (e.g., Mandarin, Bambara [see Stassen 1997: 58]), and some use (optionally, or in special conditions) a zero-predicate with an Oblique NP (e.g., Gumbainggir, Manam, present-tense Russian, etc. [Stassen 1997: 235-237]).

4. This generalization is called "Ameka's conjecture" because unlike the other hypotheses which were based on the behavior of posturals and positionals in the prototypical languages like Dutch and Tzeltal respectively, this generalization was a speculation based on behavior of such verbs in languages like Ewe, English (singleverb languages) and Likpe (a multiverb language) and had not been tested on more languages.

\section{References}

Ameka, Felix K. and Essegbey, James (2006). Elements of the Ewe grammar of space. In Grammars of Space: Cognitive Explorations, Stephen C. Levinson and David P. Wilkins (eds.), 359-399. Cambridge: Cambridge University Press.

Aristotle.Categories, translated by E. M. Edghill, University of Adelaide, ebooks@adelaide. etext.library.adelaide.edu.au/a/a8/category $/ \mathrm{html}$.

Brown, Penelope (1994). The INs and ONs of Tzeltal locative expressions: the semantics of static descriptions of location. Linguistics 32(4/5) (Special issue: Space in Mayan Languages), 743-790.

Campbell, Lyle; Kaufman, Terrence; and Smith-Stark, T. C. (1986). Meso-America as a linguistic area. Language 62(3), 530-558.

Clark, Eve V. (1978). Locationals: existential, locative and possessive constructions. In Universals of Human Language, Volume 4: Syntax, Joseph H. Greenberg (ed.), 85-126. Stanford: Stanford University Press. 
Dunn, Michael; Terrill, Angela; Reesink, Ger; Foley, Robert A.; and Levinson, Stephen C. (2005). Structural phylogenetics and the reconstruction of ancient language history. Science 309, 2072-2075.

Goddard, Cliff and Harkins, Jean (2002). Posture, location, existence, and states of being in two Central Australian languages. In The Linguistics of Sitting, Standing and Lying, John Newman (ed.), 213-238. Amsterdam: Benjamins.

Grinevald, Colette (2006). The expression of static location in a typological perspective. In Space in Languages: Linguistic Systems and Cognitive Categories, Maya Hickmann and Stephane Robert (eds.), 29-58. Amsterdam: John Benjamins.

Hellwig, Birgit (2003). The grammatical coding of postural semantics in Goemai. Unpublished doctoral dissertation, Radboud University, Nijmegen.

Keegan, John M. (1997). A Reference Grammar of Mbay. Munich: Lincom Europa.

- (2002). Posture verbs in Mbay. In The Linguistics of Sitting, Standing and Lying, John Newman (ed.), 333-358. Amsterdam: Benjamins.

Kelly, Ann and Melinger, Alissa (2001). Annual Report 2001. Nijmegen: Max Planck Institute for Psycholinguistics.

Landau, Barbara and Jackendoff, Ray (1993). What and where in spatial language and spatial cognition. Behavioral and Brain Sciences 16(2), 217-238.

Léon, Lourdes de and Levinson, Stephen C. (eds.) (1992). Spatial Description in Mesoamerican Languages. Special issue of Zeitschrift für Phonetik, Sprachwissenschaft und Kommunikationsforschung 45(6).

Levinson, Stephen C. (1992). Primer for the field investigation of spatial description and conception. Pragmatics 2(1), 5-47.

-(2000a). Presumptive Meanings: The Theory of Generalized Conversational Implicature. Cambridge, MA: MIT Press.

- (2000b). H. P. Grice on location on Rossel Island. BLS 25, 210-224.

- (2003). Space in Language and Cognition: Explorations in Cognitive Diversity. Cambridge: Cambridge University Press.

- (2006). The language of space in Yélî Dnye. In Grammars of Space: Cognitive Explorations, Stephen C. Levinson and David P. Wilkins (eds.), 157-205. Cambridge: Cambridge University Press.

— and Wilkins, D. P. (eds.) (2006). Grammars of Space. Cambridge: Cambridge University Press.

-; Meira, Sergio; and the Language and Cognition Group (2003). 'Natural concepts' in the spatial typological domain - adpositional meanings in cross-linguistic perspective: an exercise in semantic typology. Language 79(3), 485-516.

- (i. prep.) 'Put' and 'take' in Yélî Dnye. In Events of "Putting" and "Taking": A Crosslinguistic Perspective, A. Kopecka and B. Narasimhan (eds.). Typological Studies in Language. Amsterdam and Philadelphia: Benjamins.

Mithun, Marianne (1999). The Languages of Native North America. Cambridge: Cambridge University Press.

Newman, John (ed.) (2002). The Linguistics of Sitting, Standing and Lying. Amsterdam: Benjamins.

Reid, Nicholas (2002). Sit right down the back: serialised posture verbs in Ngan'gityemeri and other Northern Australian languages. In The Linguistics of Sitting, Standing and Lying, John Newman (ed.), 239-267. Amsterdam: Benjamins.

Staden, Miriam van; Bowerman Melissa; and Verhelst, Mariet (2006). Some properties of spatial description in Dutch. In Grammars of Space, Stephen C. Levinson and David P. Wilkins (eds.), 475-511. Cambridge: Cambridge University Press. 


\section{Introduction 871}

Stassen, Leon (1997). Intransitive Predication. Oxford Studies in Typology and Linguistic Theory. Oxford: Clarendon Press.

Talmy, Leonard (2000). Toward a Cognitive Semantics. 2 vols. Cambridge, MA: MIT Press.

Ungerleider, Leslie G. and Mishkin, Mortimer (1982). Two cortical systems. In Analysis of Visual Behavior, D. Ingle, M. D. Goodale, and R. J. W. Mansfield (eds.), 549-586. Cambridge, MA: MIT Press.

Watkins, Laurel (1976). Position in grammar: sit, stand, lie. Kansas Working Papers in Linguistics 1, 16-40. 
